\title{
The burden of Mycoplasma genitalium at the First Antenatal Care Visit in a Cohort of Women Infected with Human Immunodeficiency Virus in South Africa
}

M Mudau 1, J Laumen 2,3, James McIntyre², Jeffrey Klausner', Andrew Medina-Marino', Remco Peters ${ }^{2,3,5}$

1 Research Unit, Foundation for Professional Development, RSA. 2 Anova Health Institute, RSA. 3 Department Medical Microbiology Maastricht University, Netherlands. 4 David Geffen School of Medicine, UCLA, Los Angeles, CA, United States. 5 Department of Medical Microbiology, University of Pretoria, RSA

\section{BACKGROUND}

Mycoplasma genitalium (MG) is a sexually transmitted infection (STI) that is associated with several reproductive tract diseases, including vaginal discharge syndrome, preterm birth, and spontaneous abortion. Routine detection of MG with definitive diagnostic tests is not conducted in South Africa and its prevalence among pregnant women and in the general population is not well-described.

\section{OBJECTIVE}

To determine the prevalence of MG in a cohort of HIV-infected pregnant women at the first antenatal care (ANC) consultation.

\section{METHODS}

- HIV-infected pregnant women accessing antenatal care in three public were enrolled and asked to self-collect two vulvovaginal swab specimens.

- One swab specimen collected using Xpert ${ }^{\circledast}$ CT/NG Vaginal/Endocervical specimen kit (Cepheid, Sunnyvale, CA) was tested for the presence of Chlamydia trachomatis (CT), Neisseria gonorrhoeae (NG), and Trichomonas vaginalis (TV) at the point of care with the Xpert $^{\oplus} \mathrm{CT} / \mathrm{NG}$ and TV assays.

Specimens for MG testing were collected using COPAN FLOQSwabs ${ }^{\mathrm{TM}}$ and were tested using a real-time PCR assay targeting the MgPa gene'. Detection of the human beta globin housekeeping gene was used to confirm successful amplification and detection of clinical specimens.

\section{RESULTS}

- Specimens were collected from 334 participants and 296 were successfully tested for MG and were included in the current sub-study; 34 participants were excluded due to non-amplification of the control gene, while four participants were enrolled and later found to be ineligible for the study.

- The prevalence of MG was $14.5 \%$ (95\% Cl: $9.1 \%-16.7 \%)$, CT was $31.4 \%$ (95\% Cl: $26.4 \%-37.0 \%)$, NG was $4.7 \%$ (95\% Cl: $2.8 \%-7.8 \%)$, and TV was $23.3 \%$ (95\% Cl: $18.8 \%-28.5 \%)$.

- Among women infected with MG, 32.6\% were co-infected with $\mathrm{CT}$, $2.3 \%$ were co-infected with NG, and $18.6 \%$ were co-infected with TV.

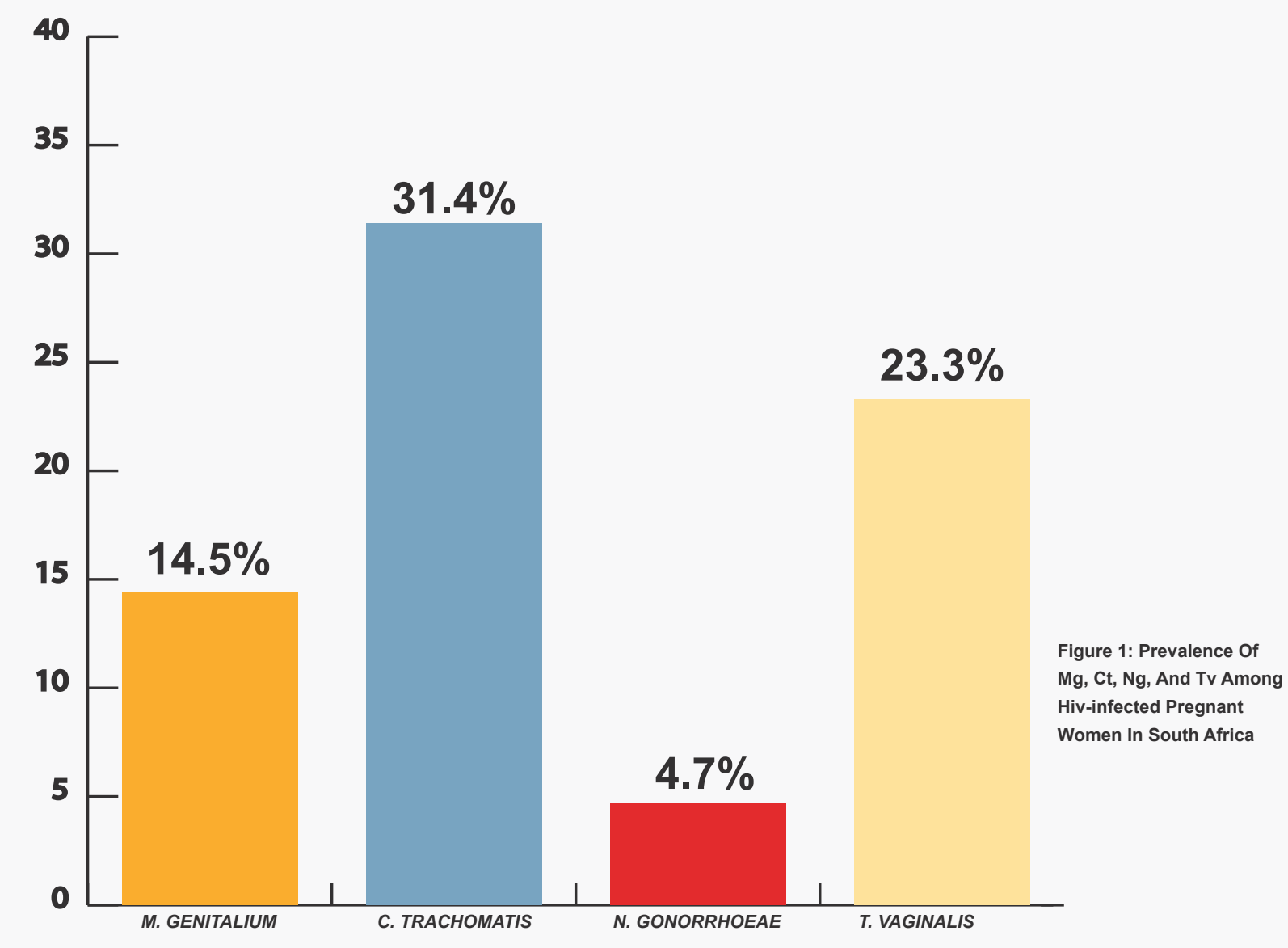

\begin{tabular}{|c|c|c|c|c|}
\hline \multirow[b]{2}{*}{ Characteristic } & \multirow[b]{2}{*}{ Total tested } & \multicolumn{2}{|c|}{ Positive for MG } & \multirow[b]{2}{*}{ p-value } \\
\hline & & $\mathbf{n}$ & row \% & \\
\hline \multicolumn{5}{|l|}{ Age Group } \\
\hline$<25$ years & 46 & 4 & $8.7 \%$ & 0.375 \\
\hline 25 - 35 years & 196 & 29 & $14.8 \%$ & \\
\hline$>35$ year & 54 & 10 & $18.5 \%$ & \\
\hline \multicolumn{5}{|l|}{ Gestational Age } \\
\hline $1^{\text {st }}$ Trimester $(1-12$ weeks $)$ & 65 & 7 & $10.8 \%$ & 0.621 \\
\hline $2^{\text {nd }}$ Trimester (13-27 weeks) & 198 & 31 & $15.7 \%$ & \\
\hline $3^{\text {rd }}$ Trimester (28 - 34 weeks) & 33 & 5 & $15.2 \%$ & \\
\hline \multicolumn{5}{|l|}{ Self-reported symptoms } \\
\hline Asymptomatic & 226 & 35 & $15.5 \%$ & 0.400 \\
\hline Symptomatic & 70 & 8 & $11.4 \%$ & \\
\hline \multicolumn{5}{|l|}{ C. trachomatis } \\
\hline Positive & 93 & 14 & $15.1 \%$ & 0.862 \\
\hline Negative & 203 & 29 & $14.3 \%$ & \\
\hline \multicolumn{5}{|l|}{ N. gonorrhoeae } \\
\hline Positive & 14 & 1 & $7.1 \%$ & 0.422 \\
\hline Negative & 282 & 42 & $14.9 \%$ & \\
\hline \multicolumn{5}{|l|}{ T. vaginalis } \\
\hline Positive & 69 & 8 & $11.6 \%$ & 0.430 \\
\hline Negative & 227 & 35 & $15.4 \%$ & \\
\hline
\end{tabular}

\section{CONCLUSION}

- The MG prevalence reported in this study is higher than prevalence reported in prior studies conducted in sub-Saharan Africa among women.

- MG prevalence was lower than that of CT and TV, but was higher than that of NG.

- Further studies are needed to investigate MG macrolide resistance and to determine the effects of $M$. genitalium infection on pregnancy outcomes.

\section{FUNDING AND ACKNOWLEDGEMENTS}

This research was supported by the Eunice Kennedy Shriver Institute of Child Health and Human Development (NICHD) of the National Institutes of Health (NIH) under award number: R21 HD084274-01A1 and the President's Emergency Plan for AIDS Relief (PEPFAR) through the United States Agency for International Development under the terms of the Cooperative Agreement AID 674-A-12-00017.

The authors would like to acknowledge the Tshwane District Department of Health and clinic managers who gave permission to conduct the study at the respective sites, the facility staff who accommodated our study teams, and the research nurses and research assistants.

Reference 